\title{
Richieri Costa-Pereira syndrome
}

INSERM

\section{Source}

INSERM. (1999). Orphanet: an online rare disease and orphan drug data base. Richieri Costa-Pereira syndrome. ORPHA:3102

Richieri Costa-Pereira syndrome is characterized by short stature, Robin sequence, cleft mandible, pre/postaxial hand anomalies (including hypoplastic thumbs), and clubfoot. It has been described in 14 Brazilian families and in one unrelated French patient. Prominent low set ears and a highly arched palate were also observed. Transmission is autosomal recessive. 